\title{
Manifestações Musculoesqueléticas em Pacientes Submetidos à Hemodiálise
}

\section{Musculoskeletal Manifestations in Patients under Hemodialysis}

\author{
Walber Pinto Vieira ${ }^{(1)}$, Kirla Wagner Poti Gomes ${ }^{(2)}$, Niedja Bezerra Frota ${ }^{(2)}$, \\ José Eyorand Castelo Branco Andrade ${ }^{(3)}$, Rejane Maria Rodrigues de Abreu Vieira ${ }^{(4)}$, \\ Francisca Edwiges Araújo Moura ${ }^{(5)}$, Francisco José Fernandes Vieira ${ }^{(5)}$
}

\section{RESUMO}

As anormalidades musculoesqueléticas em pacientes submetidos à hemodiálise são numerosas e freqüentes, sendo mais prevalentes naqueles em tratamento dialítico de longa duração. A artralgia é o sintoma mais comum, ocorrendo em mais de $70 \%$ dos pacientes. O hiperparatireoidismo secundário é a principal causa da doença renal óssea, e as manifestações clínicas são: dor óssea, artralgia e prurido. A amiloidose, decorrente da deposição de proteína ß2-microglobulina nos tecidos, manifesta-se pela presença de ombro doloroso, síndrome do túnel do carpo, dedo em gatilho, ruptura espontânea de tendão e fratura patológica. Outras manifestações musculoesqueléticas observadas são a artrite induzida por cristais, necrose avascular, artrite séptica, fraqueza muscular e cãibras musculares.

Palavras-chave: manifestações musculoesqueléticas, hemodiálise, hiperparatireoidismo, amiloidose.

\section{INTRODUÇÃO}

O desenvolvimento da diálise na década de 60 como modalidade terapêutica continuada aumentou consideravelmente a expectativa de vida dos pacientes com doença renal terminal. No mundo, cerca de 1,2 milhão de pessoas encontramse sob tratamento dialítico. No Brasil, são aproximadamente 54,5 mil pessoas, destas, 48.875 em hemodiálise e 5.649 em diálise peritoneal ${ }^{(1)}$. $\mathrm{O}$ número de pacientes em programa dialítico cresce no Brasil à média de 10\%, às custas de uma

\begin{abstract}
Musculoskeletal manifestations in hemodialysis patients are numerous and frequent, being more prevalent in those undergoing long duration dialytic treatment. Arthralgia is the most commom symptom, occurring in more than $70 \%$ of patients. Secondary hyperparathyroidism is the main cause of bone renal disease, and clinical manifestations are bone pain, arthralgia and pruritus. Amyloidosis, due to $\beta 2$-microglobulin deposition in tissues, manifests as shoulder pain, carpal tunnel syndrome, trigger finger, spontaneous tendon rupture and pathological fractures. Other musculoskeletal manifestations observed are crystal-induced arthritis, avascular necrosis, septic arthritis, muscle weakness and muscle cramps.
\end{abstract}

Keywords: musculoskeletal manifestations, hemodialysis, hyperparathyroidism, amyloidosis.

incidência de mais de cem pacientes novos por milhão de habitantes/ano ${ }^{(1)}$.

Existem muitos fatores envolvidos com a qualidade de vida do paciente com insuficiência renal crônica (IRC), e os problemas musculoesqueléticos estão entre os principais ${ }^{(2)}$. O rim participa da regulação da homeostase mineral e, com o desenvolvimento da insuficiência renal, aparecem alterações no esqueleto ${ }^{(3)}$.

A osteodistrofia renal, termo que se refere às várias doenças ósseas decorrentes da IRC, tem grande destaque ${ }^{(3)}$.

\footnotetext{
Serviço de Reumatologia do Hospital Geral de Fortaleza. Recebido em 05/01/2005. Aprovado, após revisão, em 25/07/2005.

1. Chefe do Serviço de Reumatologia do Hospital Geral de Fortaleza (HGF).

2. Médica Residente do Serviço de Reumatologia do HGF.

3. Preceptor do Serviço de Reumatologia do HGF.

4. Mestre em Reumatologia pela Universidade de São Paulo (USP), Ribeirão Preto-SP.

5. Preceptor(a) do Serviço de Reumatologia do HGF.

Endereşo para correspondência: Walber Pinto Vieira, Rua Ávila Goulart, 900, Papicu, Fortaleza, CEP 60155-290, CE, Brasil, telefone/fax: (85) 3226-2301 / 3278-1120,
} e-mail: jklia@terra.com.br 
Outras manifestações atribuídas à IRC e diálise são: deposição de alumínio, deposição de amilóide e espondiloartropatia destrutiva, ruptura de tendão, deposição de cristal, infecção e necrose avascular, entre outras ${ }^{(4)}$. Essas alterações, menos comuns que a osteodistrofia renal, são mais prevalentes em pacientes submetidos à hemodiálise por vários anos ou ao transplante renal ${ }^{(4)}$.

A artralgia é um sintoma comum entre pacientes submetidos à diálise ${ }^{(5)}$. Mais de $70 \%$ das pessoas que fazem hemodiálise relatam sintomas articulares, e a prevalência dos sintomas aumenta com a duração do tratamento ${ }^{(5,6)}$. A correlação da artralgia com achados radiográficos é pobre ${ }^{(7)}$, e a artralgia é mais freqüente que a artrite, sendo o joelho a articulação mais envolvida ${ }^{(8)}$. Os pacientes podem também relatar rigidez matinal ${ }^{(9,10)}$.

Algumas manifestações clínicas e radiológicas tornamse mais prevalentes após dez anos de diálise, como a síndrome do túnel do carpo, dor articular inflamatória, cistos ósseos e espondiloartropatias ${ }^{(9)}$. Não foi mostrada associação entre as manifestações musculoesqueléticas e sexo, etnia, idade atual dos pacientes ou idade ao iniciar a diálise ${ }^{(8)}$.

Sabendo-se que as anormalidades osteoarticulares em pacientes com insuficiência renal crônica submetidos à diálise são numerosas e freqüentes, faz-se necessário reconhecer e tratar precocemente as manifestações, na tentativa de aliviar a dor e melhorar a capacidade funcional e, conseqüentemente, a qualidade de vida dos pacientes ${ }^{(8,11)}$.

\section{MANIFESTAÇÕES \\ MUSCULOESQUELÉTICAS EM PACIENTES SUBMETIDOS À HEMODIÁLISE}

\section{DOENÇA RENAL ÓSSEA}

O termo osteodistrofia renal, introduzido em 1943 por Liu e Chu, refere-se a todos os tipos de doença óssea decorrentes da insuficiência renal ${ }^{(3,11,12)}$. A doença óssea é devida, principalmente, aos efeitos do hiperparatireoidismo secundário ${ }^{(13,14)}$.

\section{HIPERPARATIREOIDISMO SECUNDÁRIO}

O hiperparatireoidismo aparece precocemente quando a taxa de filtração glomerular encontra-se entre 60-90 $\mathrm{mL} / \mathrm{min}$, como mostrado pelos níveis séricos aumentados de paratormônio (PTH), anormalidades ósseas ao exame histopatológico e aumento uniforme das glândulas paratireóides ${ }^{(11,12)}$. As causas incluem hipocalcemia, níveis reduzidos de calcitriol, retenção de fosfato e insensibilidade da glândula paratireóide ao efeito inibitório do cálcio na secreção de $\mathrm{PTH}^{(3,12,14)}$.

Tanto a formação quanto a reabsorção óssea ocorrem de forma acelerada, devido à atividade e ao número aumentado de osteoblastos e osteoclastos ${ }^{(3,12,14)}$. Outro achado histopatológico é a fibrose medular aumentada ${ }^{(3,14)}$.

As manifestações clínicas mais encontradas são: dor óssea, desconforto articular e prurido ${ }^{(14)}$. A dor óssea é difusa, predomina nos membros inferiores, relaciona-se com as alterações de peso corporal e aparece no repouso ${ }^{(8)}$.

O produto cálcio-fósforo elevado, geralmente maior que 60-70 mg2/dL2, aumenta o risco de deposição metastática de cálcio (Figura 1) e, também, de mortalidade ${ }^{(14)}$. O valor sérico de fósforo elevado é considerado um bom preditor de mortalidade cardiovascular ${ }^{(2)}$.

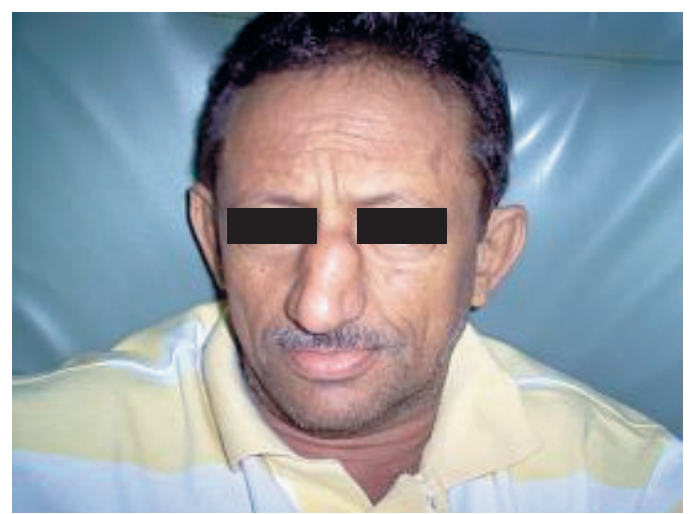

Figura 1 - Tumoração em dorso do nariz em paciente em hemodiálise por nove anos e com produto cálcio-fósforo elevado

Os níveis séricos de $\mathrm{PTH}$, fosfatase alcalina e fósforo estão elevados, enquanto os de cálcio estão normais ou reduzidos. No hiperparatireoidismo avançado, entretanto, pode haver hipercalcemia decorrente do tecido hiperplasiado autônomo da paratireóide ${ }^{(14)}$. A hipercalcemia pode surgir também com o uso de cálcio e análogos da vitamina $\mathrm{D}^{(14)}$.

Os achados radiológicos estão ausentes na doença leve, mas estão sempre presentes no hiperparatireoidismo avançado ${ }^{(14)}$. Um achado característico da osteíte fibrosa, doença óssea associada ao hiperparatireoidismo, é a reabsorção subperiosteal da face radial da segunda e terceira falanges $^{(12,14)}$. Também são observados erosão da falange distal, reabsorção óssea do crânio, dando uma aparência de "sal e pimenta" e desaparecimento da lâmina dura em dentes sem cárie (Figura 2) $)^{(3,12,14)}$. 


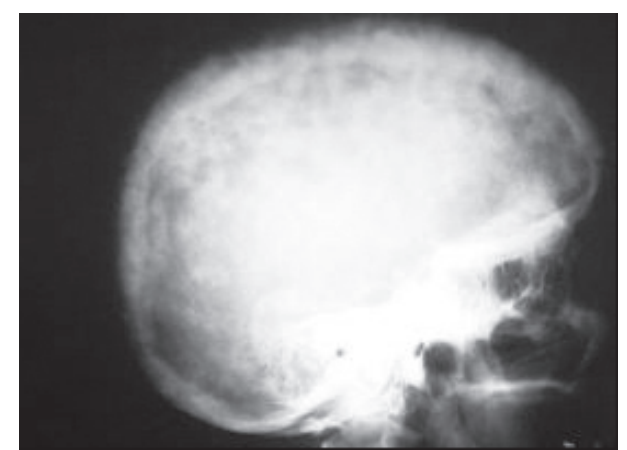

Figura 2- Aspecto de "sal e pimenta" em crânio de paciente em hemodiálise por oito anos

Em um estudo, lesões radiológicas da articulação acromioclavicular foram encontradas em $45 \%$ dos pacientes submetidos à hemodiálise, correlacionando-se com dor no ombro em 38\% dos casos (Figura 3) ${ }^{(10)}$. A dor não ocorre em repouso e não piora durante a hemodiálise, diferenciando-a da dor decorrente da amiloidose por $\beta 2$-microglobulina ${ }^{(10)}$.

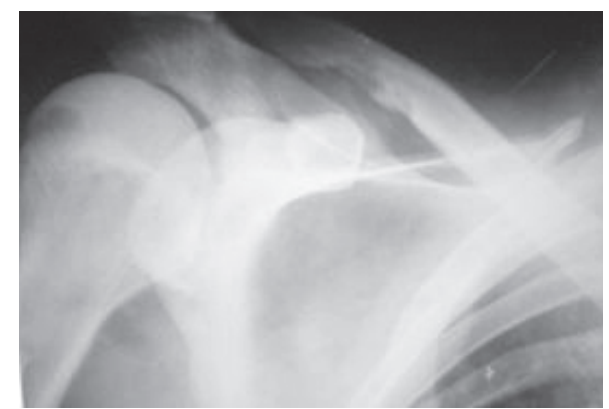

Figura 3 - Reabsorção distal da clavícula em paciente em hemodiálise por oito anos

Formação óssea desorganizada e acelerada está associada à osteíte fibrosa, podendo ser vista à radiografia como osteoesclerose ${ }^{(14)}$. Outro sinal radiológico encontrado é a calcificação de tecidos moles e vasos sangüíneos, denominado calcificação metastática (Figuras 4, 5A e 5B) $)^{(12,14)}$.

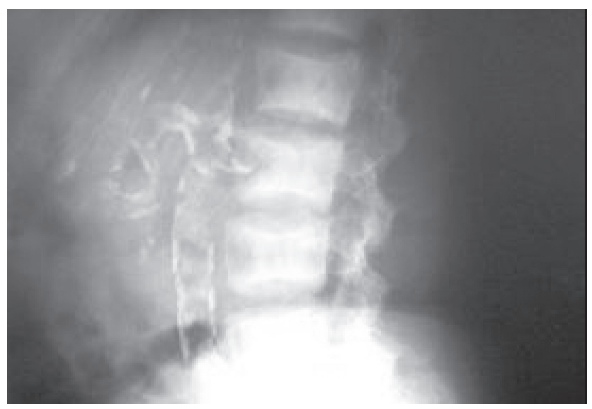

Figura 4 - Calcificação metastática de aorta abdominal em paciente em hemodiálise por 14 anos
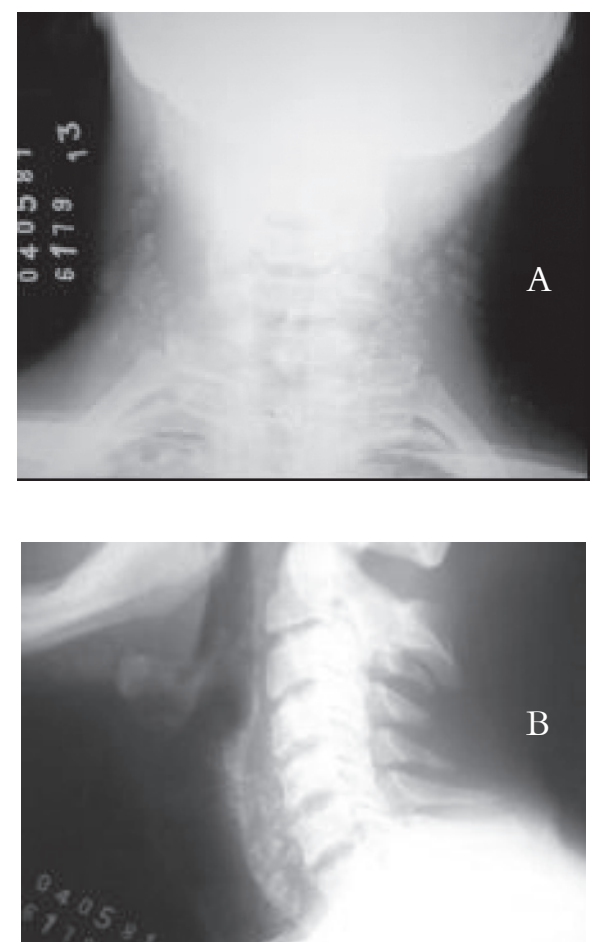

Figura 5 - Calcificação metastática cervical em paciente em hemodiálise por 14 anos

Fatores de risco para reabsorção subperiosteal associamse à duração da insuficiência renal, sexo feminino, idade jovem e doença renal não-glomerular como causa da IRC $^{(11)}$.

O tratamento é feito com a reposição de vitamina D, suplementação com cálcio e controle do nível sérico de fósforo ${ }^{(12,14)}$. No entanto, no hiperparatireoidismo grave, com produto cálcio-fósforo alto, a terapia com vitamina $\mathrm{D}$ é contra-indicada até que os níveis séricos de fósforo sejam controlados $^{(14)}$.

A suplementação com cálcio deve ser feita com acetato ou carbonato de cálcio, evitando-se o citrato, que aumenta a absorção intestinal de alumínio ${ }^{(14)}$. O nível sérico de fósforo é controlado através da baixa ingestão dietética e uso de quelantes do fósforo, de preferência não contendo alumínio, que podem ser usados em situações especiais e por período curto de tempo ${ }^{(14)}$.

Glândulas paratireóides muito aumentadas provavelmente não involuem, pois têm funcionamento autônomo, não sendo inibidas pelo calcitriol ${ }^{(12,14)}$. Esta condição é conhecida como hiperparatireoidismo terciário, que se desenvolve após vários anos de hiperparatireoidismo secundário ${ }^{(12,14)}$. Nesses casos, indica-se a paratireoidectomia ${ }^{(12,14)}$. 


\section{OSTEOMALÁCIA}

Cerca de 20-30\% dos pacientes com IRC apresentam osteomalácia, caracterizada pelo excesso de osteóide (colágeno ósseo não-mineralizado) devido à incapacidade de mineralização ${ }^{(3,11)}$. Em pacientes com doença renal que não estão ainda em diálise, a principal causa é a deficiência de vitamina $\mathrm{D}$, e tais pacientes têm níveis séricos reduzidos de 25-hidroxicolecalciferol ${ }^{(11)}$.

$\mathrm{Na}$ IRC, a restrição dietética e a anorexia contribuem para uma baixa ingestão de vitamina $\mathrm{D}^{(11)}$. Há também redução da 1,25-dihidroxicolecalciferol, metabólito da vitamina $\mathrm{D}$ produzido pelo rim $^{(3,11,14)}$. No entanto, com a instituição da diálise e a reposição precoce de vitamina D ativa, a osteomalácia torna-se menos comum ${ }^{(3,11)}$.

\section{INTOXICAÇÃO POR ALUMÍNIO}

$\mathrm{Na}$ IRC e hemodiálise, o alumínio dietético é inadequadamente eliminado, sendo depositado no osteóide do osso recém-formado, inibindo a mineralização e levando à osteomalácia ${ }^{(3,11,12)}$. Os efeitos tóxicos do alumínio podem ocorrer isoladamente ou superpostos ao hiperparatireoidismo ${ }^{(11,12,14)}$. O hiperparatireoidismo, entretanto, parece proteger contra a toxicidade óssea do alumínio e vice-versa ${ }^{(14)}$.

O quadro clínico é representado por dor óssea difusa, mais grave e incapacitante que a da osteíte fibrosa, com maior risco de fraturas, principalmente de costelas ${ }^{(12,14)}$. Outras manifestações associadas são a anemia e a demência ${ }^{(3,11,12,14)}$.

Atualmente, a doença óssea relacionada ao alumínio é menos comum, resultado do abandono do uso de quelantes do fósforo contendo alumínio e do aprimoramento dos protocolos de tratamento da água do dialisado ${ }^{(1)}$.

\section{DOENÇA ÓSSEA ADINÂMICA}

Alguns pacientes com IRC, principalmente aqueles submetidos à diálise, exibem quantidade normal de osteóide, com número reduzido de osteoblastos e osteoclastos, e taxa de formação óssea reduzida, caracterizando a doença óssea adinâmica ou aplástica ${ }^{(3,11,12,14)}$. A espessura do osteóide, entretanto, é normal ou reduzida, diferenciando-a da osteomalácia, e os níveis séricos de PTH são geralmente menores que $100 \mathrm{pg} / \mathrm{mL}^{(14)}$. Os baixos valores de fosfatase alcalina podem ser um bom teste preditivo desta condição ${ }^{(14)}$.

A causa é desconhecida, mas os fatores de risco associados são a diálise peritoneal, diabetes e idade avançada ${ }^{(3,14)}$. Calcificações vasculares são vistas com freqüência e, devido aos pacientes serem geralmente assintomáticos, a necessidade de intervenção não é ainda certa ${ }^{(14)}$.

\section{AMILOIDOSE POR ß2-MICROGLOBULINA}

As manifestações clínicas da amiloidose raramente são observadas em pacientes não submetidos a tratamento dialítico ${ }^{(5)}$. Não há diferença de prevalência entre amiloidose associada à hemodiálise e à diálise peritoneal ambulatorial contínua $(\mathrm{CAPD})^{(5)}$. A deposição de proteína $\beta 2$-microglobulina aumenta com a duração da hemodiálise, de $21 \%$ em dois anos para 100\% após mais de $13 \operatorname{anos}^{(3,5)}$, e envolve principalmente o sistema osteoarticular ${ }^{(15)}$.

Em pacientes submetidos à diálise, a taxa de produção da $\beta 2$-microglobulina é maior que a de remoção, resultando em concentrações séricas aumentadas em até 60 vezes $^{(5,16)}$. A presença de ombro doloroso, síndrome do túnel do carpo e contraturas em flexão dos quirodáctilos em pacientes submetidos à hemodiálise a longo prazo é muito sugestiva de amiloidose por $\beta 2$-microglobulina ${ }^{(5,16)}$. Outras manifestações relacionadas são o dedo em gatilho, ruptura espontânea de tendão, hemartrose e fratura patológica ${ }^{(11,17)}$.

\section{OMBRO DOLOROSO}

Ombro doloroso acomete até $84 \%$ dos pacientes em hemodiálise por dez anos ou mais e é geralmente bilateral ${ }^{(5,18)}$. A dor piora com o decúbito dorsal, especialmente durante $\mathrm{o}$ procedimento e à noite ${ }^{(5,10,19)}$.

A deposição de $\beta 2$-microglobulina na bursa subacromial e no manguito rotador pode levar à síndrome do impacto ${ }^{(5,12,19)}$. Foi observado que todos os pacientes com ombro doloroso, sem outra patologia que possa ser responsável pela condição, têm espessamento do tendão do músculo supra-espinhoso à ultrassonografia ${ }^{(18)}$. A capsulite adesiva pôde também ser observada ${ }^{(5)}$.

É importante distinguir o tipo de dor no ombro, pois a ressecção do ligamento coracoacromial pode aliviar os sintomas e a dor noturna e de decúbito ${ }^{(19,20)}$.

\section{SÍNDROME DO TÚNEL DO CARPO}

A síndrome do túnel do carpo é decorrente da compressão do nervo mediano pelos depósitos da proteína ${ }^{(5)}$. É a característica clínica mais comum da amiloidose, estando presente em até $74 \%$ dos pacientes em hemodiálise por dez anos ou mais, ocorrendo tanto em pacientes submetidos à hemodiálise quanto diálise peritoneal ${ }^{(3,5,11)}$.

A exacerbação dos sintomas durante a hemodiálise pode ser decorrente do roubo arterial induzido pela fístula, causando isquemia do nervo mediano ${ }^{(5)}$. Entre as sessões de diálise, o aumento de líquido extracelular pode levar a edema no túnel do carpo e compressão do nervo ${ }^{(5)}$. 


\section{CONTRATURA EM FLEXÃO DOS QUIRODÁCTILOS}

A contratura em flexão dos quirodáctilos é decorrente da deposição de proteína amilóide $\beta 2$-microglobulina ao longo dos tendões flexores dos $\operatorname{dedos}^{(5)}$. A prevalência aumenta com a duração da diálise ${ }^{(5)}$.

\section{ESPONDILOARTROPATIA DESTRUTIVA}

O esqueleto axial pode estar acometido em cerca de $10 \%$ dos pacientes submetidos à diálise a longo prazo, apresentando-se na forma de espondiloartropatia destrutiva ${ }^{(5,12)}$. A coluna cervical baixa é a mais afetada, mas pode envolver também a coluna torácica e lombar ${ }^{(5)}$.

Depósitos de proteína amilóide 32 -microglobulina foram demonstrados em ligamentos paravertebrais e discos intervertebrais de pacientes com essa espondiloartropatia ${ }^{(5)}$. As alterações radiológicas incluem estreitamento dos espaços intervertebrais e erosão das lâminas vertebrais terminais sem a formação perceptível de osteófitos ou esclerose ${ }^{(5,12)}$. A maioria dos pacientes com alterações radiológicas, entretanto, não possui manifestações clínicas ${ }^{(5,12)}$.

A dor cervical é o sintoma inicial ${ }^{(5)}$. Manifestações neurológicas são raras e apresentam-se como radiculopatia cervical ou mielopatia decorrente da deposição de $\beta 2$-microglobulina no canal vertebral ${ }^{(5,12)}$.

\section{Cistos ósseos}

Cistos amilóides subcondrais, mais encontrados nos ossos do carpo, podem ocorrer no acetábulo e em ossos longos ${ }^{(5)}$. São vistos tipicamente adjacentes às articulações, diferentemente dos tumores marrons do hiperparatireoidismo ${ }^{(5)}$.

Apresentam-se como lesões radiotransparentes, eventualmente com interrupção do córtex, mas sem reação periosteal ${ }^{(5)}$. Os cistos são de tamanho variável $(2-3 \mathrm{~mm}$ de diâmetro nos ossos do carpo até $40 \mathrm{~mm}$ no acetábulo), aumentando em número e tamanho com o tempo de tratamento dialítico ${ }^{(5)}$.

Fraturas patológicas podem ocorrer em regiões de osso enfraquecido por depósito de amilóide, especialmente no colo do fềmur ${ }^{(3,5)}$.

\section{MANIFESTAÇÕES SISTÊMICAS}

Depósitos viscerais de $\beta 2$-microglobulina podem ser encontrados em pacientes submetidos a tratamento dialítico por longo prazo, geralmente por um período superior a dez $\operatorname{anos}^{(5)}$. A deposição aumenta com o tempo de diálise, mas a extensão do envolvimento sistêmico permanece controversa ${ }^{(5)}$.

A 32-microglobulina visceral, diferentemente da proteína osteoarticular, que se deposita no interstício, é depositada em vasos sangüíneos e, embora tenha sido responsabilizada por complicações cardiovasculares e gastrintestinais, geralmente não causa sintomas ${ }^{(5,21)}$.

O diagnóstico de amiloidose secundária à diálise é sugerido pelo quadro clínico, inicialmente, e pelas alterações radiológicas. A identificação histológica da $\beta 2$-microglobulina pelo vermelho-congo é considerada "padrão-ouro" para o diagnóstico ${ }^{(5,12,22)}$.

O tratamento da amiloidose por $\beta 2$-microglobulina é sintomático, podendo-se usar antiinflamatórios não esteroidais (AINEs), corticosteróide oral e intra-articular, além de fisioterapia ${ }^{(5)}$. A cirurgia é reservada para pacientes sintomáticos com grandes depósitos de proteína amilóide $^{(5)}$.

O transplante renal geralmente estabiliza a doença e leva a um rápido alívio da dor osteoarticular, embora a regressão dos depósitos de $\beta 2$-microglobulina provavelmente não ocorra ${ }^{(11,23,24)}$. A melhora do quadro musculoesquelético nesses casos, entretanto, pode ser devida ao uso de corticosteróides $^{(24)}$. Em relação à prevenção, o transplante renal precoce em pacientes sem depósitos significativos da proteína é a medida mais efetiva ${ }^{(5)}$.

\section{ARTRITE INDUZIDA POR CRISTAIS}

As manifestações clínicas da artrite induzida por cristais são semelhantes, fazendo-se necessária a pesquisa de cristais no líquido sinovial para a distinção ${ }^{(5)}$. Os cristais envolvidos são: pirofosfato de cálcio diidratado, urato monossódico, hidroxiapatita e oxalato de cálcio(5).

\section{PSEUDOGOTA}

Os cristais de pirofosfato de cálcio diidratado causam artrite em pacientes em hemodiálise mais comumente que os cristais de urato monossódico, principalmente quando o hiperparatireoidismo é mal controlado ${ }^{(5)}$. Afeta geralmente articulações médias ou grandes, como os joelhos, mas as primeiras metatarsofalangianas também podem ser acometidas $^{(5,25)}$. As crises agudas são caracterizadas por início súbito de dor articular intensa associada a edema, eritema e calor, decorrente da liberação dos cristais para o espaço $\operatorname{articular}^{(5,25)}$.

O estudo do líquido sinovial revela muitos neutrófilos e cristais em forma de bastão com birrefringência fracamente positiva $^{(5,25)}$. A radiografia das articulações envolvidas pode mostrar condrocalcinose, que é geralmente assintomática, sendo a apresentação mais comum do depósito de cristais de pirofosfato de cálcio diidratado (Figura 6) ${ }^{(5,25)}$. 


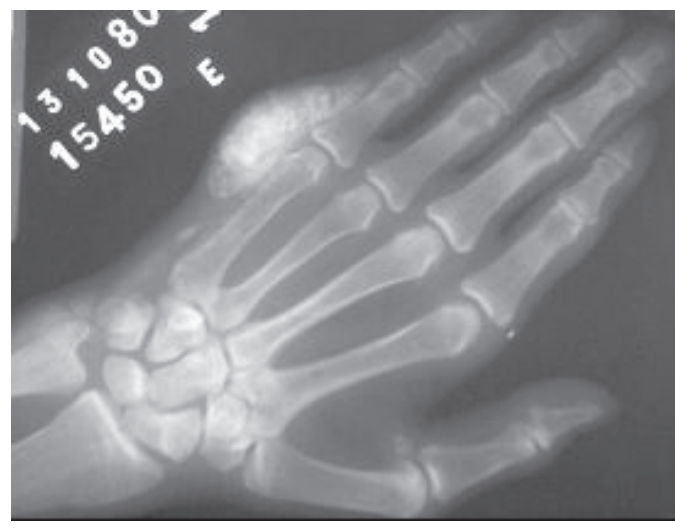

Figura 6 - Calcificação periarticular em paciente em hemodiálise por 14 anos

As crises agudas podem resolver espontaneamente, mas o uso de AINE e a punção articular com ou sem injeção de corticosteróide podem ser úteis ${ }^{(5,25)}$.

\section{GOTA}

As crises de artrite gotosa são comuns em pacientes hiperuricêmicos antes do início da terapia dialítica, mas raras em pacientes já em hemodiálise ${ }^{(5,11)}$. Quando a artrite gotosa aguda continua após a instituição da hemodiálise, os episódios são mais brandos ${ }^{(5)}$.

O quadro clínico é semelhante ao da pseudogota, apesar de as pequenas articulações serem as mais acometidas, como a primeira metatarsofalangiana ${ }^{(5,26)}$. O diagnóstico é feito através de punção articular e visualização de cristais em formato de agulha ou bastão, com birrefringência fortemente negativa à luz polarizada compensada ${ }^{(5,26)}$.

A resposta é rápida à terapia com AINE, corticosteróide oral ou intra-articular ${ }^{(5)}$. A colchicina pode também ser usada $^{(5)}$. O alopurinol é indicado nos casos de artrite gotosa de repetição, mas em dose baixa $(100 \mathrm{mg} /$ dia $)$, pelo fato de a medicação ter excreção renal ${ }^{(5)}$.

\section{ARTROPATIA ASSOCIADA A CRISTAIS DE HIDROXIAPATITA}

Os cristais de hidroxiapatita causam artrite principalmente quando o produto cálcio-fósforo excede $75 \mathrm{mg}^{2} / \mathrm{dL}^{2(5,12,27)}$. O controle da hiperfosfatemia e do hiperparatireoidismo ajuda a prevenir a deposição dos cristais ${ }^{(5)}$.

A articulação mais acometida é a do ombro, mas pode haver depósito dos cristais em torno do quadril, punho, tornozelo, cotovelo e pequenas articulações da mão ${ }^{(5,27)}$. A calcificação de tendão, ligamento e cápsula articular pode estar associada a processo inflamatório doloroso periarticular $^{(5)}$. A doença articular por cristais de hidroxiapatita associa-se também à artropatia destrutiva ${ }^{(28)}$.
Pode ocorrer calcinose tumoral, decorrente do crescimento dos depósitos, especialmente em ombros, formando massas palpáveis e visíveis ${ }^{(5,27,29)}$. A calcifilaxia, desordem caracterizada por calcificação de partes moles, calcificação vascular e necrose isquêmica da pele, geralmente é vista em associação com níveis elevados de fosfato sérico ${ }^{(9,29)}$.

Os cristais, por serem de pequeno tamanho, geralmente não são vistos quando o líquido sinovial é examinado por microscopia de luz polarizada compensada, mas podem ser visualizados quando o líquido é corado com vermelho $\mathrm{S}$ de alizarina ${ }^{(5,27)}$.

O tratamento é feito com AINEs, colchicina ou punção articular com ou sem injeção de corticosteróide ${ }^{(5,27)}$. A redução das concentrações de fósforo, através da redução da ingestão dietética de fosfato, interrupção do uso de vitamina $\mathrm{D}$ e uso de quelantes de fosfato, foi associada à diminuição da dor no ombro e à calcificação periarticular ${ }^{(5)}$. A cirurgia para remoção dos depósitos pode ser utilizada quando o tratamento conservador falhar ${ }^{(5,27)}$.

\section{ARTROPATIA ASSOCIADA A CRISTAIS DE OXALATO DE CÁLCIO}

Cristais de oxalato de cálcio podem causar sinovite aguda e crônica tanto em pacientes em hemodiálise quanto em diálise peritoneal ${ }^{(5)}$. As pequenas articulações são as mais envolvidas (Figura 7), e a condrocalcinose pode ser evidente à radiografia das articulações afetadas ${ }^{(5)}$.

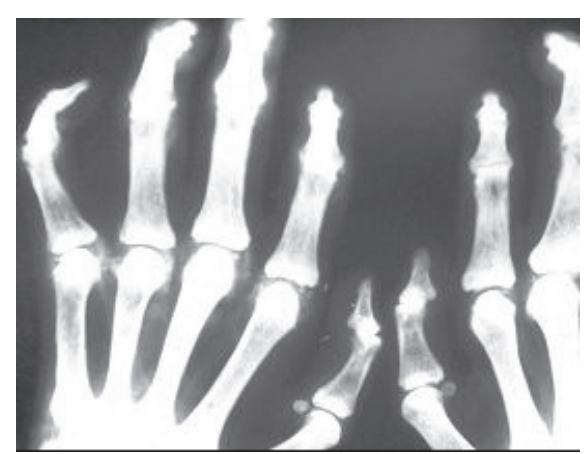

Figura 7 - Cisto ósseo e calcificação periarticular de articulações das mãos em paciente em hemodiálise por oito anos

O diagnóstico é feito pela visualização, no líquido sinovial, de cristais bipiramidais, fortemente birrefringentes, à microscopia de luz polarizada compensada ${ }^{(5,27)}$. A coloração positiva com vermelho $\mathrm{S}$ de alizarina confirma a presença de cálcio nos cristais $^{(5)}$. Os cristais de oxalato de cálcio podem também se depositar na musculatura lisa vascular, resultando em acrocianose e livedo reticular ${ }^{(5)}$. 
A resposta a AINEs, colchicina ou corticosteróide intraarticular é precária ${ }^{(5)}$. Deve-se ter cautela ao prescrever suplementos vitamínicos para pacientes em diálise, pois a vitamina C (ácido ascórbico) é metabolizada a oxalato, aumentando os níveis séricos de oxalato e exacerbando a oxalose ${ }^{(5,12,27)}$.

\section{OSTEONECROSE}

A prevalência de osteonecrose em pacientes submetidos à hemodiálise varia de 3 a $18 \%$, sendo a cabeça do fềmur o local mais freqüentemente acometido ${ }^{(5,28)}$. Está mais comumente associada ao transplante renal e ao uso de corticosteróides, acometendo de 5 a $30 \%$ dos pacientes transplantados ${ }^{(28)}$.

\section{ARTRITE SÉPTICA}

A artrite séptica ocorre com maior freqüência em pacientes submetidos à hemodiálise devido à necessidade e estabelecimento de acesso vascular diversas vezes por semana ${ }^{(5,16,30)}$. O agente etiológico mais envolvido é o Staphylococcus aureus $^{(5)}$.

A doença é geralmente monoarticular, e o quadro clínico é de dor, derrame, calor e redução da amplitude do movimento articular ${ }^{(5,30,31)}$. Febre, leucocitose e anormalidades radiográficas podem estar ausentes ${ }^{(5,30,31)}$.

O diagnóstico é feito através de punção articular e cultura do líquido sinovial para bactérias, micobactérias e fungos ${ }^{(5,30,31)}$.

O tratamento é feito com antibiótico parenteral por duas semanas, seguido de antibiótico oral por mais duas a quatro semanas, além de drenagem da articulação afetada ${ }^{(5,31)}$.

\section{RUPTURA ESPONTÂNEA DE TENDÃO}

É relativamente comum a ruptura espontânea de tendão em pacientes em diálise crônica, podendo ser vista em até 15\% deles ${ }^{(5,17)}$. Geralmente está associada ao hiperparatireoidismo secundário, mas pode também estar relacionada à amiloidose por $\beta 2$-microglobulina ${ }^{(5,17,30)}$. O tendão do quadríceps é o mais acometido ${ }^{(5,30)}$.

A reparação cirúrgica deve ser prontamente realizada ${ }^{(5,30)}$. $\mathrm{O}$ tratamento medicamentoso visa controlar a dor e o hiperparatireoidismo secundário ${ }^{(5)}$.

\section{BURSITE OLECRANIANA}

Geralmente ocorre no lado ipsilateral ao da fistula arteriovenosa, sendo decorrente de microtraumas oriundos da pressão mantida sobre o cotovelo durante as sessões repetidas de diálise $\mathrm{e}^{(5,8)}$.

A aspiração da bolsa alivia os sintomas e, através da cultura do líquido, permite descartar processo infeccioso ${ }^{(5)}$. A injeção de corticosteróide pode reduzir a recorrência, e a excisão cirúrgica fica reservada para casos refratários ${ }^{(5)}$.

\section{FRAQUEZA MUSCULAR}

A fraqueza muscular generalizada associada à diálise afeta predominantemente os membros inferiores e a musculatura proximal $^{(5,30)}$. Os níveis séricos de enzimas musculares estão normais e a eletromiografia mostra aumento anormal em potências de unidade motora polifásicas inespecíficas ${ }^{(5,30)}$. O histopatológico revela atrofia de fibras do tipo $\mathrm{II}^{(5)}$.

A etiologia costuma ser multifatorial, mas a principal causa é a deficiência de vitamina $\mathrm{D}^{(5,30)}$. Outras causas associadas são o hiperparatireoidismo, intoxicação por alumínio, neuropatia periférica, toxicidade por drogas (corticosteróides, colchicina), alterações nas concentrações de cálcio e fósforo e calcificação vascular provocando isquemia ${ }^{(5,30)}$. A inatividade física também está envolvida na patogênese da fraqueza muscular ${ }^{(5,30,32)}$.

Tem sido implicada, também, como causa da miopatia urêmica, a transferência prejudicada de oxigênio capilar para o músculo ${ }^{(2)}$. Nesses casos, obtém-se melhora da miopatia com exercícios progressivos de resistência ${ }^{(2)}$.

\section{CÃIBRAS MUSCULARES}

As cãibras musculares ocorrem em até $20 \%$ dos tratamentos de hemodiálise ${ }^{(33)}$. A patogênese não é totalmente conhecida, mas está provavelmente relacionada à ultrafiltração rápida, hiponatremia e hipotensão ${ }^{(3,5,30,33)}$. Pacientes urêmicos, porém ainda sem tratamento dialítico, não apresentam cãibras com freqüência ${ }^{(30)}$.

A administração de sulfato de quinino e o ganho de pouco peso entre as sessões de diálise ajudam a prevenir as cãibras $^{(33)}$.

\section{CONCLUSÃO}

As manifestações musculoesqueléticas em pacientes submetidos à hemodiálise são bastante comuns, especialmente naqueles em tratamento dialítico de longa duração. As anormalidades mais importantes para a Reumatologia são: artralgia, presente em mais de $70 \%$ dos pacientes, ombro doloroso, síndrome do túnel do carpo e dedo em gatilho, decorrentes da deposição de proteína $\beta 2$-microglobulina nos tecidos. Outras alterações também importantes são: artrite induzida por cristais, necrose avascular, artrite séptica, fraqueza muscular e cãibras musculares.

Conhecendo as alterações musculoesqueléticas associadas à hemodiálise, o reumatologista torna-se apto a reconhecer e resolver os problemas inerentes a esse tipo de patologia. 


\section{REFERÊNCIAS}

1. Sociedade Brasileira de Nefrologia; www.sbn.org.br; 2003.

2. Bardin T: Musculoskeletal manifestations of chronic renal failure. Curr Opin Rheumatol 15:48-54, 2003.

3. Negrea A: Osteodistrofia renal. In: Hricik D, Sedor J, Ganz M. Segredos em Nefrologia, $3^{\mathrm{a}}$ ed., Porto Alegre, Artmed, 2002.

4. Murphey MD, Sartoris DJ, Pathria MN, Martin NL: Musculoskeletal manifestations of chronic renal insufficiency. Radiographics 13:35779, 1993

5. Kay J, Hano J: Doenças musculoesqueléticas e reumatológicas. In: Daugirdas J, Blake P, Ing T. Manual de Diálise, $3^{\text {a }}$ ed., Belo Horizonte, Medsi, 2003.

6. Foissac-Gegoux P, Flipo RM, Hardouin P, et al.: Current aspects of the osteoarticular pathology of hemodialysis patients. Results and discussion of a rheumatological survey. Nephrologie 7:157-63, 1986.

7. Chou CT, Wasserstein A, Schumacher HR Jr, Fernandez P: Musculoskeletal manifestations in hemodialysis patients. J Rheumatol 12:1149-53, 1985

8. Braz A, Duarte A: Manifestações musculoesqueléticas nos pacientes em programa de hemodiálise. Rev Bras Reumatol 43:223-31, 2003.

9. Hardouin P, Flipo RM, Foissac-Gegoux P, et al.: Current aspects of osteoarticular pathology in patients undergoing hemodialysis: study of 80 patients. Part 1. Clinical and radilogical analysis. J Rheumatol 14:780-3, 1987.

10. Mayet WJ, Hermann E, Wandel E, et al.: Rheumathologic and radiologic symptoms of secondary hyperparathyroidism: retrospective long-term study of 175 chronic hemodialysis patients. Z Rheumatol 50:313-9, 1991.

11. Fortina F, Agllata S, Ragazzoni E, et al.: Chronic pain during dialysis. Pharmacologic therapy and its costs. Minerva Urol Nefrol 51:85-7, 1999.

12. Eastwood J, Pazianas M: Renal bone disease. In: Klippel J, Dieppe P. Rheumatology, $2^{\text {a }}$ ed., Londres, Mosby, 1998.

13. Jarek M: Rheumatic disorders in the dialysis patients. In: West $\mathrm{S}$. Rheumatology Secrets. $2^{a}$ ed., Philadelphia, Hanley \& Belfus, Inc., 2002.

14. Delmez J, Kay J: Doença óssea. In: Daugirdas J, Blake P, Ing T. Manual de Diálise, 3a. ed., Belo Horizonte, Medsi, 2003.

15. Bardin T, Zingraff J, Benoit J, Kuntz D, Druek T: Amyloidosis in hemodialysis patients. Presse Med 16:907-10, 1987.

16. Kay J, Bardin T: Osteoarticular disorders of renal origin: disease-related and iatrogenic. Baillieres Best Pract Res Clin Rheumatol 14:285-305, 2000 .
17. Kurer MH, Baillod RA, Madgwick JC: Musculoskeletal manifestations of amyloidosis. A review of 83 patients on haemodialysis for at least 10 years. J Bone Joint Surg Br 73:271-6, 1991.

18. Sommer R, Valen GJ, Ori Y, et al: Sonographic features of dyalisisrelated amyloidosis of the shoulder. J Ultrasound Med 19:765-70, 2000.

19. Konishiike $\mathrm{T}$, Hashizume $\mathrm{H}$, Nishida $\mathrm{K}$, Inoue $\mathrm{H}$, Nagoshi $\mathrm{M}$ : Shoulder pain in long-term haemodialysis patients. A clinical study of 166 patients. J Bone Joint Surg Br 78:601-5, 1996.

20. Nagoshi $M$, Hashizume $H$, Konishiike $T$, Kawai $A$, Inoue $H$ : Hemodialysis-related subacromial lesion: diagnostic imaging and minimally invasive treatment. Clin Nephrol 54:112-20, 2000.

21. Ullian ME, Hammond WS, Alfrey AC, Schultz A, Molitoris BA: Beta-2-microglobulin-associated amyloidosis in chronic hemodialysis patients with carpal tunnel syndrome. Medicine (Baltimore) 68:107-15, 1989.

22. Buxbaum J: The amyloidoses. In: Klippel J, Dieppe P. Rheumatology. $2^{\mathrm{a}}$ ed., Londres, Mosby, 1998.

23. Drueke TB: Beta2-microglobulin and amyloidosis. Nephrol Dial Transplant 15:17-24, 2000 .

24. Bardin T, Lebail-Darne JL, Zingraff J, et al.: Dialysis arthropathy: outcome after renal transplantation. Am J Med 99:243-8, 1995.

25. Carpenter M: Calcium pyrophosphate dihydrate deposition disease. In: West S. Rheumatology Secrets. $2^{\mathrm{a}}$ ed., Philadelphia, Hanley \& Belfus, Inc., 2002.

26. Janson R: Gout. In: West S. Rheumatology Secrets. $2^{\text {a }}$ ed., Philadelphia, Hanley \& Belfus, Inc., 2002.

27. Carpenter M: Hydroxiapatite and other crystalline diseases. In: West S. Rheumatology Secrets. $2^{\mathrm{a}}$ ed., Philadelphia, Hanley \& Belfus, Inc., 2002.

28. Bardin T, Fritz P: Rheumathological complications of dialysis. Ann Radiol (Paris) 36:74-80, 1993.

29. Alem A, Sherrard D: Renal Osteodystrophy. In: Henrich WL. Principles and Practice of Dialysis, $2^{\mathrm{a}}$ ed., Baltimore, Williams \& Wilkins, 1999

30. Massry SG: Divalent ion metabolism and renal osteodystrophy. In: Massry SG, Glassock RJ. Textbook of Nephrology, $3^{\text {a }}$ ed., Baltimore, Williams \& Wilkins, 1995.

31. Gilliland W: Bacterial septic arthritis. In: West S. Rheumatology Secrets. $2^{a}$ ed., Philadelphia, Hanley \& Belfus, Inc., 2002.

32. Kemp GJ, Crowe AV, Anijeet HK, et al.: Abnormal mitochondrial function and muscle wasting, but normal contractile efficiency, in haemodialysed patients studied non-invasively in vivo. Nephrol Dial Transplant 19:1520-7, 2004.

33. Negrea L: Complicações da hemodiálise. In: Hricik D, Sedor J, Ganz M. Segredos em Nefrologia. Porto Alegre, Artmed, 2002. 